\title{
MOLECULAR DESCRIPTION OF COPPER (I) OXIDE AND COPPER (II) OXIDE
}

\author{
Wei Gao ${ }^{\mathrm{a}, *}$, Muhammad Imran, ${ }^{\mathrm{b}, \mathrm{c}}$ Muhammad Kamran Siddiqui ${ }^{\mathrm{b}, \mathrm{d}}$, Muhammad Naeem ${ }^{\mathrm{e}}$ and Farrukh Jamil ${ }^{\mathrm{f}}$ \\ ${ }^{a}$ School of Information Science and Technology, Yunnan Normal University, Kunming, 650500, China \\ ${ }^{b}$ Department of Mathematical Sciences, United Arab Emirates University, P. O. Box 15551, Al Ain, United Arab Emirates \\ 'Department of Mathematics, School of Natural Sciences, National University of Sciences and Technology, Sector H-12, Islamabad, \\ 44000, Pakistan \\ ${ }^{\mathrm{d} D e p a r t m e n t ~ o f ~ M a t h e m a t i c s, ~ C O M S A T S ~ U n i v e r s i t y ~ I s l a m a b a d, ~ S a h i w a l ~ C a m p u s, ~ 57000, ~ P a k i s t a n ~}$ \\ eDepartment of Mathematics, The University of Lahore, Pakpattan Campus, 57400 Pakistan \\ fDepartment of Biosciences, COMSATS University Islamabad, Sahiwal Campus, 57000, Pakistan
}

Recebido em 14/03/2018; aceito em 30/05/2018; publicado na web em 12/07/2018

\begin{abstract}
The topological index of a molecular structure correlate certain physicochemical properties such as boiling point and stability of that molecular structure. Recently several topological indices have been introduced and studies have shown their association with certain physical and chemical properties of other molecules. Specifically, Zagreb, Atom-bound connectivity (ABC) and Sanskruti indices have been correlated with extent of branching, enthalpy and entropy of some organic molecules. In this study we have calculated Zagreb, Atom-bound connectivity (ABC) and Sanskruti indices (S) for Copper (I) oxide and Copper (II) oxide CuO. Additionally, from the experimentally available data, we calculated entropy and enthalpy per unit cell for both the oxides and compared with Atombound connectivity and Sanskruti indices. It appears that these indices have very poor relation with these physical properties in both oxides of copper and they may need some modifications to show considerable compliance as reported in other organic molecules."
\end{abstract}

Keywords: molecular graphs; zagreb indices; atom-bound connectivity index; sanskruti index; copper oxide.

\section{INTRODUCTION}

"A graph that shows constituents of a molecule and their connectivity is known as molecular graph and such representation is usually referred as topological representation of molecule. ${ }^{1}$ Molecular graphs

"are usually characterized by different topological indices for correlation of chemical structure of a molecule with biological, chemical or physical properties. Studies have reported several applications of different topological indices in quantitative structure-activity relationship (QSAR) and quantitative structure-property relationship (QSPR), virtual screening and computational drug designing. ${ }^{2-7}$

"So far, many different topological indices have been developed, and most of them are only graph descriptors. ${ }^{8-18}$ Only a few indices have shown their correlation with biological, chemical or physical chemical properties of certain molecules. ${ }^{19-21}$ For example, Zagreb indices $\left(M_{1} \& M_{2}\right)$ were first reported by Gutman and Trinajestic for the correlation of chemical structure with $\varpi$ electrons. ${ }^{22}$ However, later $M_{1}$ and $M_{2}$ were associated with extent of branching in a molecule. They are described by equation (1) \& (2) for a graph $\mathrm{G}=(\mathrm{V}, \mathrm{E})$, where $\mathrm{V}$ to be the vertex set and $E$ to be the edge set of $G$. The degree $d_{p}$ of the vertex $p$ is the quantity of edges of $G$ incident with $p$. The length of a most limited path in a graph $\mathrm{G}$ is a distance $\mathrm{d}(\mathrm{p}, \mathrm{q})$ amongst $\mathrm{p}$ and q."

$$
\begin{aligned}
& \boldsymbol{M}_{1}(\boldsymbol{G})=\Sigma_{p q \in E(\boldsymbol{G})}\left(\mathrm{d}_{\mathrm{p}}+\mathrm{d}_{\mathrm{q}}\right) \\
& \boldsymbol{M}_{2}(\boldsymbol{G})=\Sigma_{p q \in E(\boldsymbol{G})}\left(\mathrm{d}_{\mathrm{p}} \cdot \mathrm{dq}\right)
\end{aligned}
$$

"Another topological index is atom-bound connectivity (ABC) that was introduced by Estrada et al. ${ }^{23,24}$ Later, studies have reported its exceptional correlation with thermodynamic

\footnotetext{
*e-mail: gaowei@ynnu.edu.cn
}

properties of organic molecules, specifically with heat of formation of alkanes. This index is characterized by Equation (3) considering the graph similar to Zagreb indices"

$$
\mathbf{A B C}(\mathbf{G})=\sum_{\mathbf{p q \in E}(\mathbf{G})} \sqrt{\frac{d_{p}+d_{q}-2}{d_{p} \cdot d_{q}}}
$$

"Another molecular descriptor that was correlated with thermodynamic properties is Sankruti index. This index was introduced in 2016 by S. M. Hosamani and it shows considerable correlation with entropy of some organic molecules. ${ }^{25}$ It is characterized as equation (4) considering the above mentioned graph conditions"

$$
\mathbf{S}(\mathbf{G})=\sum_{\mathbf{p q \in E}(\mathbf{G})}\left(\frac{\mathbf{s}_{\mathrm{p}} \times \mathbf{s}_{\mathbf{q}}}{\mathbf{s}_{\mathrm{p}}+\mathbf{s}_{\mathbf{q}}-2}\right)^{3}
$$

"This study is designed to calculate Zagreb, ABC and Sanskruti indices for two oxides of $\boldsymbol{C u}\left(\boldsymbol{C u O} \& \boldsymbol{C u}_{2} \boldsymbol{O}\right)$. It will allow us to compare these indices with the experimentally determined entropy, enthalpy and other physical properties of $\mathrm{CuO}$ and $\mathrm{Cu}_{2} \mathrm{O}$."

\section{THEORY AND METHODS}

\section{Structure of copper (I) oxide $\left(\mathrm{Cu}_{2} \mathrm{O}\right)$}

$\mathrm{Cu}_{2} \mathrm{O}$ is a naturally occurring reddish ore that is mainly used in chemical sensors, solar oriented cells, photo-catalysis and batteries. ${ }^{26-28}$ Crystal structure of $\boldsymbol{C} \boldsymbol{u}_{2} \boldsymbol{O}$ is composed on small cubic unit cells based on $\mathrm{Cu}$ and $\mathrm{O}$ atoms (Figure. 1a). Analysis of the crystal lattice showed that each $\mathrm{Cu}$ atom is linked with two $\mathrm{O}$ atoms; in turn every $\mathrm{O}$ atom is connected with four $\mathrm{Cu}$ atoms (Figure 1b)" 


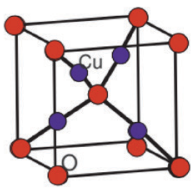

(a)

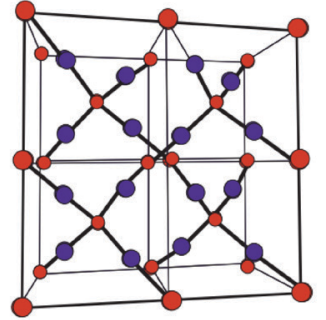

(b)
Figure 1. Copper(I) oxide . A) Unit cell of . B) Three dimensional crystal lattice of $\mathrm{Cu}$ and $\mathrm{O}$ are shown in blue and red spheres, respectively

Here, we have considered monolayer of $\boldsymbol{C} \boldsymbol{u}_{2} \boldsymbol{O}$ for convenience. To determine the indices for $\boldsymbol{C u}_{2} \mathrm{O}$ we choose the settings of this graph as; $\boldsymbol{G} \cong \boldsymbol{C u}_{2} \boldsymbol{O}[\mathrm{m}, \mathrm{n}]$ be the chemical graph of $\boldsymbol{C} \boldsymbol{u}_{2} \boldsymbol{O}$ with $(m \times n)$ unit cells in the plane. More preciously, $m$ represents the number of unit cells in row and $n$ represents the number of unit cells in column. Also for our convenience we represents $\boldsymbol{C} \boldsymbol{u}_{2} \boldsymbol{O}[\mathrm{m}, \mathrm{n}]$ as a graph G. The Figure 1(b) is representing $\mathrm{Cu}_{2} \mathrm{O}[2,2]$. Also Figure 2 represent one sheet view of Copper(I) oxide $\boldsymbol{C u}_{2} \boldsymbol{O}[4,4]$. Computational analysis showed that the quantity of vertices and edges of $\boldsymbol{C} \boldsymbol{u}_{2} \boldsymbol{O}[\mathrm{m}, \mathrm{n}]$ are $7 m n+2 m+2 n+2$ and $8 m n$, respectively. In $\boldsymbol{C} \boldsymbol{u}_{2} \boldsymbol{O}[\mathrm{m}, \mathrm{n}]$, the number of zero degree vertices is 4 , the number of one degree vertices is $4 m+4 n-4$, the number of two degree vertices is $6 m n-2 m-2 n+2$ and the number of four degree vertices is $m n$ (Table 1)."

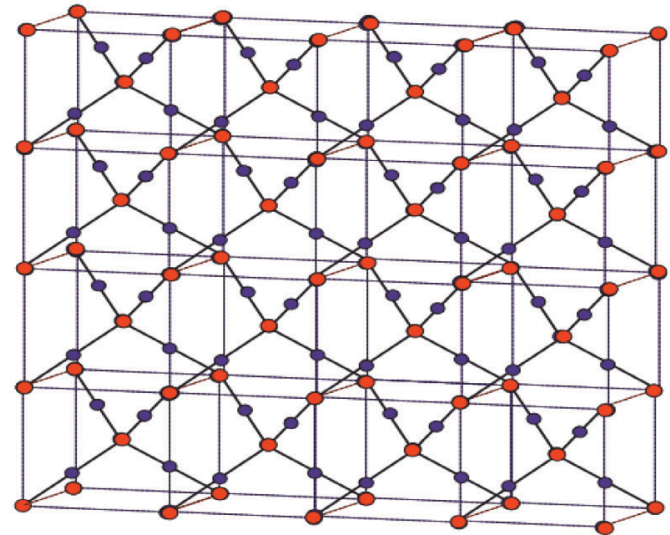

Figure 2. One sheet view of copper(I) oxide [4, 4]

Table 1. Degree based partition of edges of $\mathrm{Cu}_{2} \mathrm{O}[\mathrm{m}, n]$ for end vertices of each edge (Degree based partition edges of $\mathrm{Cu}_{2} \mathrm{O}$

\begin{tabular}{cc}
\hline$(d p, d q)$ & Frequency \\
\hline$(1,2)$ & $4 n+4 m-4$ \\
$(2,2)$ & $4 m n-4 n-4 m+4$ \\
$(2,4)$ & $4 m n$ \\
\hline
\end{tabular}

In the next Theorem, we have computed the exact result of first and second Zagreb index for the chemical graph $\mathrm{Cu}_{2} \boldsymbol{O}[m, n] . "$

Theorem 1. "Consider the graph of $\boldsymbol{G} \cong \boldsymbol{C \boldsymbol { u } _ { 2 }} \boldsymbol{O}[\mathrm{m}, \mathrm{n}]$ with m, $\mathrm{n} \geq 1$, then its first and second Zagreb index is equal to,"

$M_{1}(\mathrm{G})=40 \mathrm{mn}-4 \mathrm{~m}-4 \mathrm{n}+4$

$M_{2}(\mathrm{G})=48 \mathrm{mn}-8 \mathrm{~m}-8 \mathrm{n}+8$
Proof. "Let $\mathrm{G}$ be the crystallographic structure of [m, n].The first Zagreb index is computed as below:"

$M_{1}(G)=\Sigma_{p q \in E(G)}\left(\mathrm{d}_{\mathrm{p}}+\mathrm{d}_{\mathrm{q}}\right)$

“ $M_{1}(G)=(4 \mathrm{n}+4 \mathrm{~m}-4)(1+2)+(4 \mathrm{mn}-4 \mathrm{n}-4 \mathrm{~m}-4)(2+2)+(4 \mathrm{mn})(2+4)$

$M_{1}(G)=40 m n-4 m-4 n+4$.'

"By using Table 1 and Equation 1 the second Zagreb index are computed as below:"

$M_{2}(G)=\Sigma_{p q \in E(G)}\left(\mathrm{d}_{\mathrm{p}} \cdot \mathrm{dq}\right)$

" $M_{2}(G)=(4 m+4 n-4)(1 \times 2)+(4 m n-4 m-4 n+4)(2 \times 2)+(4 m n)(2 \times 4)$

$M_{2}(G)=48 m n-8 m-8 n+8$.'

"In the next Theorem, we have computed the exact result of $\mathrm{ABC}$ index for the chemical graph $\boldsymbol{C} \boldsymbol{u}_{2} \boldsymbol{O}[\mathrm{m}, \mathrm{n}] . "$

Theorem 2. "Consider the graph of $\boldsymbol{G} \cong \boldsymbol{C} \boldsymbol{u}_{2} \boldsymbol{O}[\boldsymbol{m}, \boldsymbol{n}]$ with m, $\mathrm{n} \geq 1$, then its $\mathrm{ABC}$ index is equal to,"

$\mathrm{ABC}(\mathrm{G})=4 \sqrt{ } 2(\mathrm{mn}-1)$

Proof. "Let $\mathrm{G}$ be the chemical graph of $\mathrm{Cu}_{2} \boldsymbol{O}[\boldsymbol{m}, \boldsymbol{n}]$. Then by using Table 1 and equation (3) the ABC index is computed as below:"

$$
\begin{aligned}
\operatorname{ABC}(G)= & \sum_{\mathrm{pq} \in \mathrm{E}(\mathrm{G})} \sqrt{\frac{\mathrm{d}_{\mathrm{p}}+\mathrm{d}_{\mathrm{q}}-2}{\mathrm{~d}_{\mathrm{p}} \cdot \mathrm{d}_{\mathrm{q}}}} \\
\mathrm{ABC}(\mathrm{G})= & (4 \mathrm{n}+4 \mathrm{~m}-4) \sqrt{\frac{1+2-2}{1 \times 2}}+(4 \mathrm{mn}-4 \mathrm{n}-4 \mathrm{~m}-4) \sqrt{\frac{2+2-2}{2 \times 2}} \\
& +4 \mathrm{mn} \sqrt{\frac{4+2-2}{4 \times 2}}
\end{aligned}
$$$$
\mathrm{ABC}(\mathrm{G})=4 \sqrt{ } 2(\mathrm{mn}-1)
$$

"The Table 2 shows partition of edges of the chemical graph $\boldsymbol{C} \boldsymbol{u}_{2} \boldsymbol{O}[\mathrm{m}, \mathrm{n}]$ depending on the sum of degrees of the neighbouring vertices of end vertices of each edge."

"The next Theorem shows the exact value of Sanskruti index of $\boldsymbol{C u}_{2} \boldsymbol{O}[\mathrm{m}, \mathrm{n}]$."

Table 2. Edge partition of the graph of $\boldsymbol{C} \boldsymbol{u}_{2} \boldsymbol{O}[m, n]$ with $m, n \geq 2$, based on the degree sum of vertices lying at unit distance from end vertices of each edge

\begin{tabular}{cc}
\hline$(S p, S q)$ & Frequency \\
\hline$(2,4)$ & $4 m+4 n-4$ \\
$(4,6)$ & $4 m n-4 m-4 n+4$ \\
$(5,8)$ & $4 n+4 m-4$ \\
$(6,8)$ & $4 m n-4 m-4 n+4$ \\
\hline
\end{tabular}

Theorem 3. "Consider the graph $\boldsymbol{G} \cong \boldsymbol{C \boldsymbol { u } _ { 2 }} \boldsymbol{O}[\mathrm{m}, \mathrm{n}]$ with m, n $\geq 2$, then its Sanskruti index $\mathrm{S}(\mathrm{G})$ is equal"

$\mathrm{S}(\mathrm{G})=64 \mathrm{mn}-\frac{185892 m}{1331}-\frac{185892 n}{1331}+\frac{185892}{1331}$

Proof. "Let $\mathrm{G}$ be the crystallographic structure of $\boldsymbol{C} \boldsymbol{u}_{2} \boldsymbol{O}[\mathrm{m}, \mathrm{n}]$. Then by using Table 2 and equation (4) the Sanskruti index $\mathrm{S}(\mathrm{G})$ is computed as follows."

$S(G)=\sum_{p q \in E(G)}\left(\frac{s_{p} \times s_{q}}{s_{p}+s_{q}-2}\right)^{3}$ 
$S(G)=(4 m+4 n-4)\left(\frac{2 \times 4}{2+4-2}\right)^{3}+(4 m n-4 m-4 n-4)\left(\frac{6 \times 4}{6+4-2}\right)^{3}$

$$
+(4 m+4 n-4)\left(\frac{5 \times 8}{5+8-2}\right)^{3}+(4 m n-4 m-4 n-4)\left(\frac{6 \times 8}{6+8-2}\right)^{3}
$$

$\mathrm{S}(\mathrm{G})=64 \mathrm{mn}-\frac{185892 m}{1331}-\frac{185892 n}{1331}+\frac{185892}{1331}$

\section{Structure of copper(II) oxide $(\mathrm{CuO})$}

The crystal structure of Copper(II) oxide $(\boldsymbol{C u} \boldsymbol{O})$ is composed on monoclic unit cells (Figure 3a). Here we have considered monolayer of $\boldsymbol{C u} \boldsymbol{O}$ for convenience. To find the indices we choose the settings of this graph as; let $\boldsymbol{G} \cong \boldsymbol{C u} \boldsymbol{O}[\mathrm{m}, \mathrm{n}]$ be the chemical graph of $\boldsymbol{C u O}$ with $(\mathrm{m} \times \mathrm{n})$ unit cells in the plane. The Figure $3 \mathrm{~b}$ is representing the lattice of $\boldsymbol{C u} \boldsymbol{O}[4,4]$. Computational analysis showed that number of vertices and edges of $\boldsymbol{C u} \boldsymbol{O}[\mathrm{m}, \mathrm{n}]$ are $8 \mathrm{mn}+2 \mathrm{~m}+2 \mathrm{n}$ and $12 \mathrm{mn}$, respectively. In $\boldsymbol{C u} \boldsymbol{O}[\mathrm{m}, \mathrm{n}]$ the number of one degree vertices are $2 \mathrm{n}$, the number of two degree vertices are $2 m n+4 m+2 n$, the number of three degree vertices are $4 m n-2 n$ and the number of four degree vertices are $2 \mathrm{mn}-2 \mathrm{~m} . "$

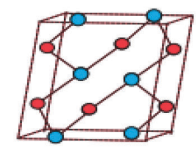

(a)

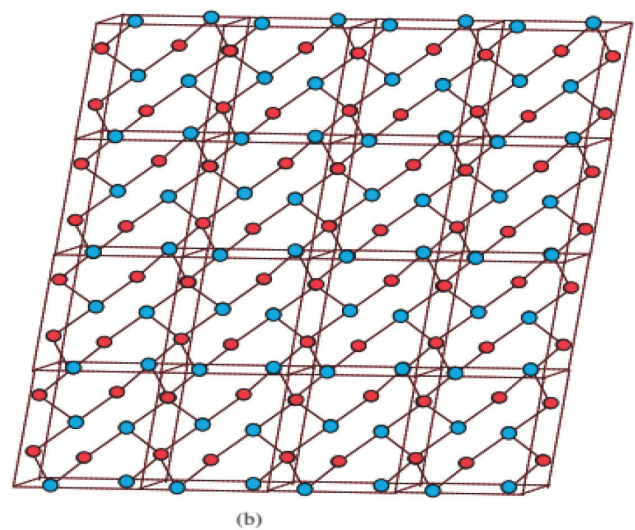

Figure 3. Copper (II) oxide CuO: (a) is the unit cell with blue and red circles represents copper and oxygen atom, respectively $(b)$ shows the lattice $\mathrm{CuO}[4,4]$

In the next Theorem, we have computed the exact value of first and second Zagreb index for the chemical graph $\mathbf{C u O}[\mathrm{m}$, $n] . "$

Table 3. Degree based partition of edges of $\boldsymbol{C u} \boldsymbol{O}[m, n]$, of end vertices of each edge

\begin{tabular}{cc}
\hline$(d p, d q)$ & Frequency \\
\hline$(1,2)$ & 2 \\
$(1,4)$ & $2 n-2$ \\
$(2,2)$ & $2 n+2$ \\
$(2,3)$ & $4 m n+8 m-6$ \\
$(3,4)$ & $8 m n-8 m-4 n+4$ \\
\hline
\end{tabular}

Theorem 4. "Consider the graph of $\mathrm{G} \sim=\boldsymbol{C} \boldsymbol{U} \boldsymbol{O}[\mathrm{m}, \mathrm{n}]$ with $\mathrm{m}, \mathrm{n} \geq 1$, then its first and second Zagreb index is equal to," $\mathrm{M}_{1}(\mathrm{G})=76 \mathrm{mn}-16 \mathrm{~m}-10 \mathrm{n}+2$

$M_{2}(G)=120 m n-48 m-32 n+16$
Proof. "Let G be the crystallographic structure of $\boldsymbol{C u} \boldsymbol{O}[\mathrm{m}, \mathrm{n}]$. The first Zagreb index is computed as:

$$
\begin{aligned}
& M_{1}(G)=\sum_{p q \in E(G)}\left(\mathrm{d}_{\mathrm{p}}+\mathrm{d}_{\mathrm{q}}\right) \\
& " M 1(G)=(2)(1+2)+(2 n-2)(1+4)+(2 n+2)(2+2) \\
& +(4 m n+8 m-6)(2+3)+(8 m n-8 m-4 n+4)(3+4) \\
& M 1(G)=76 m n-16 m-10 n+2 " \\
& M_{2}(G)=\Sigma_{p q \in E(G)}\left(\mathrm{d}_{\mathrm{p}} \cdot \mathrm{dq}\right) \\
& " M_{2}(G)=(2)(1 \times 2)+(2 n-2)(1 \times 4)+(2 n+2)(2 \times 2)+ \\
& (4 m n+8 m-6)(2 \times 3)+(8 m n-8 m-4 n+4)(3 \times 4) \\
& M_{2}(G)=120 m n-48 m-32 n+16 "
\end{aligned}
$$

"In the next Theorem, we have computed the exact result of $\mathrm{ABC}$ index for the chemical graph $\boldsymbol{C u} \boldsymbol{O}[\mathrm{m}, \mathrm{n}] . "$

Theorem 5. "Consider the graph of $\mathrm{G} \sim=\boldsymbol{C u} \boldsymbol{O}[\mathrm{m}, \mathrm{n}]$ with $\mathrm{m}$, $\mathrm{n} \geq 1$, then its $\mathrm{ABC}$ index is equal to"

$$
\begin{aligned}
\mathrm{ABC}(\mathrm{G})= & \sqrt{2}+\frac{(2 n-2) \sqrt{3}}{2}+\frac{(2 n+2) \sqrt{2}}{2}+\frac{(4 m n+8 m-6) \sqrt{2}}{2} \\
& +\frac{(8 m n-8 m-4 n+6) \sqrt{15}}{6}
\end{aligned}
$$

Proof. Let $\mathrm{G}$ be the chemical graph of $\mathrm{CuO}[\mathrm{m}, \mathrm{n}]$. Then by using Table 3 and equation (3) the ABC index is computed as below:

$$
\begin{aligned}
\mathrm{ABC}(\mathrm{G})= & \sum_{\mathrm{pq} \in \mathrm{E}(\mathrm{G})} \sqrt{\frac{\mathrm{d}_{\mathrm{p}}+\mathrm{d}_{\mathrm{q}}-2}{\mathrm{~d}_{\mathrm{p}} \cdot \mathrm{d}_{\mathrm{q}}}} \\
\mathrm{ABC}(\mathrm{G})= & (2) \sqrt{\frac{1+2-2}{1 \times 2}}+(2 \mathrm{n}-2) \sqrt{\frac{1+4-2}{1 \times 4}}+(2 \mathrm{n}+2) \sqrt{\frac{2+2-2}{2 \times 2}} \\
& +(4 \mathrm{mn}+8 \mathrm{~m}-6) \sqrt{\frac{3+2-2}{3 \times 2}}+(8 \mathrm{mn}-8 \mathrm{~m}-4 \mathrm{n}+4) \cdot \sqrt{\frac{3+4-2}{3 \times 4}} \\
\mathrm{ABC}(\mathrm{G})= & \sqrt{2}+\frac{(2 n-2) \sqrt{3}}{2}+\frac{(2 n+2) \sqrt{2}}{2}+\frac{(4 m n+8 m-6) \sqrt{2}}{2} \\
& +\frac{(8 m n-8 m-4 n+6) \sqrt{15}}{6}
\end{aligned}
$$

"The Table 4 shows partition of edges of the chemical graph $\mathbf{C u} \boldsymbol{O}[\mathrm{m}, \mathrm{n}]$, which depends on the sum of degrees of the neighboring vertices."

Table 4. Edge partition of the graph of $\mathrm{CuO}[\mathrm{m}, \mathrm{n}]$ with $\mathrm{m}, \mathrm{n} \geq 2$

\begin{tabular}{cc}
\hline$(\boldsymbol{S} \boldsymbol{p}, \boldsymbol{S} \boldsymbol{q})$ & Frequency \\
$(2,4)$ & 2 \\
$(4,5)$ & 4 \\
$(4,6)$ & 2 \\
$(4,9)$ & $2 n-2$ \\
$(5,6)$ & $2 n+2$ \\
$(6,6)$ & $12 m-12$ \\
$(6,9)$ & $2 n-2$ \\
$(5,10)$ & $2 n-2$ \\
$(6,10)$ & $4 m n-4 m-4 n+4$ \\
$(9,10)$ & $4 n-4$ \\
$(10,12)$ & $8 m n-8 m-8 n+8$ \\
\hline
\end{tabular}

The next Theorem shows the exact value of Sanskruti index of $\boldsymbol{C u O}[\mathrm{m}, \mathrm{n}]$. 
Theorem 6. "Consider the graph $\mathbf{G} \sim=\mathrm{CuO}[\mathrm{m}, \mathrm{n}]$ with $m, n \geq 2$, then its Sanskruti index $S(G)$ is equal to:"

$\mathrm{S}(\mathrm{G})=\frac{101843355285146}{137310366375}-\frac{7613496016592 n}{7689380517}-\frac{63583488 m}{42875}+\frac{700704 m n}{343}$

Proof. Let $\mathrm{G}$ be the crystallographic structure of $\boldsymbol{C u} \boldsymbol{O}[\mathrm{m}$, n]. Then by using Table 4 and equation (4) the Sanskruti index $\mathrm{S}(\mathrm{G})$ is computed as follows:

$$
\begin{aligned}
\mathrm{S}(\mathrm{G}) & =\sum_{\mathrm{pq} \in \mathrm{E}(\mathrm{G})}\left(\frac{\mathrm{S}_{\mathrm{p}} \times \mathrm{S}_{\mathrm{q}}}{\mathrm{S}_{\mathrm{p}}+\mathrm{S}_{\mathrm{q}}-2}\right)^{3} \\
\mathrm{~S}(\mathrm{G})= & (2)\left(\frac{2 \times 4}{2+4-2}\right)^{3}+(4)\left(\frac{4 \times 5}{4+5-2}\right)^{3}+(2)\left(\frac{4 \times 6}{4+6-2}\right)^{3}+(2 n-2)\left(\frac{4 \times 9}{4+9-2}\right)^{3} \\
& +(2 n+2)\left(\frac{5 \times 6}{5+6-2}\right)^{3}+(12 m-12)\left(\frac{6 \times 6}{6+6-2}\right)^{3}+(2 n-2)\left(\frac{6 \times 9}{6+9-2}\right)^{3} \\
& +(2 n-2)\left(\frac{5 \times 10}{5+10-2}\right)^{3}+(4 n-4)\left(\frac{9 \times 10}{9+10-2}\right)^{3}+(4 m n-4 m-4 n+4)\left(\frac{6 \times 10}{6+10-2}\right)^{3} \\
& +(8 m n-8 m-8 n+8)\left(\frac{10 \times 12}{10+12-2}\right)^{3}
\end{aligned}
$$$$
\mathrm{S}(\mathrm{G})=\frac{101843355285146}{137310366375}-\frac{7613496016592 n}{7689380517}-\frac{63583488 m}{42875}+\frac{700704 m n}{343}
$$

\section{RESULTS AND DISCUSSIONS}

"In this section we have compared the first (M1) and second Zegrab (M2) indices of Copper(I) oxide $\boldsymbol{C} \boldsymbol{u}_{2 o}$ and Copper(II) oxide $\mathbf{C u O}$ which is shown in Table 5. Analysis of the data showed that both the indices are higher in $\mathbf{C u O}$ compared to those of . For instance, M1(CuO)/M1() for [1,1] cell is 1.44 and the ratio increases to 1.943 for $[7,7]$ and then it decrease to 1.87 for $[10,10]$ cell. On the other hand, M2(CuO)/M2() for $[1,1]$ is 1.40 and the ratio gradually increases to 2.413 for $[10,10]$ cell."

"Comparison of $\mathrm{ABC}$ indices for both the oxides of Copper showed higher values for $\mathbf{C u O}$ compared to those of (Table 6). For example, ratio of $\mathrm{ABC}(\mathbf{C u O}) / \mathrm{ABC}()$ for $[2,2]$ cell is 1.95 and it decreases to 1.44 for $[10,10]$. This shows its decreasing trend with the increase of cells."

"In the Table 7, we gave a comparison of the Sanskruti indices of Copper(I) oxide $\boldsymbol{C} \boldsymbol{u}_{2 o}$ and Copper(II) oxide $\boldsymbol{C u} \boldsymbol{O}$. Analysis of the data showed that host higher Sanskruti index

Table 5. Comparison of the first and second Zegrab indices of Copper(I) oxide $\boldsymbol{C} \boldsymbol{u}_{2 o}$ and Copper(II) oxide $\boldsymbol{C u} \boldsymbol{O}$

\begin{tabular}{ccccc}
\hline$[n, m]$ & $M_{1}\left(\mathrm{Cu}_{2} \boldsymbol{O}\right)$ & $M_{1}(\boldsymbol{C u O})$ & $M_{2}\left(\mathrm{Cu}_{2} \boldsymbol{O}\right)$ & $M_{2}(\mathrm{CuO})$ \\
\hline$[1,1]$ & 36 & 52 & 40 & 56 \\
{$[2,2]$} & 148 & 254 & 168 & 336 \\
{$[3,3]$} & 340 & 608 & 392 & 856 \\
{$[4,4]$} & 612 & 1114 & 712 & 1616 \\
{$[5,5]$} & 964 & 1772 & 1128 & 2616 \\
{$[6,6]$} & 1396 & 2582 & 1640 & 3856 \\
{$[7,7]$} & 1908 & 3544 & 2248 & 5336 \\
{$[8,8]$} & 2500 & 4858 & 2952 & 7056 \\
{$[9,9]$} & 3172 & 5924 & 3752 & 9016 \\
{$[10,10]$} & 3924 & 7342 & 4648 & 11216 \\
\hline
\end{tabular}

Table 6. Comparison of the $A B C$ index of Copper(I) oxide $\boldsymbol{C u}_{2} \boldsymbol{O}$ and

\begin{tabular}{|c|c|c|c|c|c|c|}
\hline \multirow{2}{*}[n,m]{} & \multicolumn{2}{|c|}{$\begin{array}{l}\text { Formula } \\
\text { Units }\end{array}$} & \multirow{2}{*}{$S\left(\mathrm{Cu}_{2} \mathrm{O}\right)$} & \multirow{2}{*}{$S(\mathrm{CuO})$} & \multicolumn{2}{|c|}{$($ Entropy $) \times\left(10^{-23}\right) \mathrm{kJ}$} \\
\hline & $\mathrm{Cu}_{2} \mathrm{O}$ & $\mathrm{CuO}$ & & & $\mathrm{Cu}_{2} \mathrm{O}$ & $\mathrm{CuO}$ \\
\hline$[2,2]$ & 16 & 20 & 1037.0 & 3966.9 & 247.04 & 142.8 \\
\hline$[3,3]$ & 36 & 42 & 2577.682945 & 11708.13692 & 555.84 & 299.88 \\
\hline$[4,4]$ & 64 & 72 & 4846.356123 & 23535.09049 & 988.16 & 514.08 \\
\hline$[5,5]$ & 100 & 110 & 7843.029301 & 39447.78166 & 1544 & 785.4 \\
\hline$[6,6]$ & 144 & 156 & 11567.70248 & 59446.21045 & 2223.36 & 1113.84 \\
\hline$[7,7]$ & 196 & 210 & 16020.37566 & 83530.37685 & 3026.24 & 1499.4 \\
\hline$[8,8]$ & 256 & 272 & 21201.04884 & 111700.2809 & 3952.64 & 1942.08 \\
\hline$[9,9]$ & 324 & 342 & 27109.72201 & 143955.9225 & 5002.56 & 2441.88 \\
\hline$[10,10]$ & 400 & 420 & 33746.39519 & 180297.3017 & 6176 & 2998.8 \\
\hline
\end{tabular}
Copper(II) oxide $\boldsymbol{C u} \boldsymbol{O}$

\begin{tabular}{ccccccc}
\hline & \multicolumn{2}{c}{ Formula Units } & $A B C$ & $A B C$ & $\begin{array}{c}\text { (Heat of formation }) \\
\times(10)^{-23} \mathrm{~kJ}\end{array}$ \\
\cline { 2 - 7 }$[n, m]$ & $\boldsymbol{C} \boldsymbol{u}_{\mathbf{2}} \boldsymbol{O}$ & $\boldsymbol{C u} \boldsymbol{O}$ & $\boldsymbol{C u}_{\mathbf{2}} \boldsymbol{O}$ & $\boldsymbol{C u} \boldsymbol{O}$ & $\boldsymbol{C \boldsymbol { u } _ { 2 } \boldsymbol { O }}$ & $\boldsymbol{C u} \boldsymbol{O}$ \\
\hline$[1,1]$ & 4 & 6 & 0 & 8.4852 & 112.88 & 155.4 \\
{$[2,2]$} & 16 & 20 & 16.970 & 33.519 & 451.52 & 518 \\
{$[3,3]$} & 36 & 42 & 45.254 & 74.538 & 1592 & 1087.8 \\
{$[4,4]$} & 66 & 65 & 64.254 & 102.42 & 1947 & 1836.5 \\
{$[5,5]$} & 100 & 110 & 135.76 & 204.53 & 2822 & 2849 \\
{$[6,6]$} & 144 & 156 & 197.99 & 293.50 & 4063.68 & 4040.4 \\
{$[7,7]$} & 196 & 210 & 271.53 & 398.46 & 5531.12 & 5439 \\
{$[8,8]$} & 256 & 272 & 356.38 & 519.41 & 7224.32 & 7044.8 \\
{$[9,9]$} & 324 & 342 & 452.54 & 656.34 & 9143.28 & 8857.8 \\
{$[10,10]$} & 400 & 420 & 560.02 & 809.25 & 11288 & 10878 \\
\hline
\end{tabular}

Table 7. Comparison of the Sanskruti indices of Copper(I) oxide $\mathrm{Cu}_{2} \boldsymbol{O}$ and Copper(II) oxide $\mathbf{C u} \boldsymbol{O}$

compared to $\mathbf{C u O}$. The $\mathrm{S}(\mathbf{C u O}) / \mathrm{S}()$ for $[2,2]$ is 3.825 and it increases to 5.34 for $[10,10]$. This shows its increasing trend with the increase of cells."

A topological index is a numerical value that is calculate form molecular graph for explaining the relationship of chemical structure with physiochemical properties. So far, several applications of different indices have been reported for organic molecules, such as entropy and enthalpy determination, chirality identification, ${ }^{9} \mathrm{ZE}$-isomerism ${ }^{10}$ and heterosystem studies. ${ }^{18}$ The topological indices can be very helpful for crystalline compounds to correlate their structure with physiochemical properties. Therefore, we have determined Zagreb, ABC and Sunskurti indices for $\boldsymbol{C} \boldsymbol{u}_{2} \boldsymbol{O}$ and $\boldsymbol{C u} \boldsymbol{O}$. Additionally, we compared these indices with the physical properties these oxides as described in Pubchem (https:// pubchem.ncbi.nlm.nih.gov/)."

"Zagreb indices (M1 \& M2) were initially considered for total energy of $\varpi$-electrons in organic molecules. ${ }^{12}$ However, later they were associated with extent of branching in a molecular graph [10,11]. Analyses revealed higher $M 1$ and $M 2$ for $\boldsymbol{C u} \boldsymbol{O}$ compared to those of $\boldsymbol{C} \boldsymbol{u}_{2} \boldsymbol{O}$ at any cubic level i.e. at any equal value of $(\mathrm{m} \times \mathrm{n})$ (Table 5$)$. It suggests more branching in $\boldsymbol{C u} \boldsymbol{O}$ compared to $\boldsymbol{C} \boldsymbol{u}_{\mathbf{2}} \boldsymbol{O}$. It may cause more compact $\boldsymbol{C u} \boldsymbol{O}$ (Density: $\left.6.315 \mathrm{~g} / \mathrm{cm}^{3}\right)$ structure compared to $\mathrm{Cu} 2 \mathrm{O}\left(6.0 \mathrm{~g} / \mathrm{cm}^{3}\right)$. 
Moreover, higher melting point of $\boldsymbol{C u} \boldsymbol{O}$ (1599 K) compared to that of $\boldsymbol{C \boldsymbol { u } _ { 2 }} \boldsymbol{O}(1505 \mathrm{~K})$ may also be associated to the higher branching."

" $A B C$ indices of $\boldsymbol{C} \boldsymbol{u}_{2} \boldsymbol{O}$ and $\boldsymbol{C u} \boldsymbol{O}$ were calculated at different unit cells as shown in Table 6. Analysis of the data showed higher $A B C$ indices for $\boldsymbol{C} \boldsymbol{O} \boldsymbol{O}$ compared to those of $\boldsymbol{C} \boldsymbol{u}_{2} \boldsymbol{O}$ (Table $6)$. Figure 4 shows that $A B C$ indices increase exponentially with number of cells $(m \times n)$ for both the oxides of copper. On the other hand, a linear relation of $\mathrm{ABC}$ index was observed with formula units (Figure 5). Since, $A B C$ index has previously been linked with the thermodynamic properties" of different alkanes, 7,11 "therefore, we determined the heat of formation per different units cells of both the oxides from the reported real molar enthalpy of formations (Table 6). For example, experimental molar enthalpy for $\boldsymbol{C u} \boldsymbol{O}$ is $-156 \mathrm{~kJ} \mathrm{~mol}^{-1}$ so for one formula unit it will be $-156 / 6.022 \times 10^{-23} \mathrm{~kJ}$. The obtained value then multiplied with the number of formula units present in each cell to get the enthalpy for the cell. Similarly, enthalpy for $\boldsymbol{C} \boldsymbol{u}_{2} \boldsymbol{O}$ calculated considering standard molar enthalpy -170 $\mathrm{kJ} \mathrm{mol}^{-1}$ (Table 6). Analysis of the data showed that $A B C$ index is not strongly associated with enthalpy of formation for the oxides of copper as reported in case of alkanes. ${ }^{6,13}$ " Therefore we determined a mathematical relationship, by using equation generator (http://www.1728.org/threepts.htm), between the $A B C$ indices and the heat of formation of both the oxides of copper as below:

Heat of formation for $\boldsymbol{C} \boldsymbol{u}_{2} \boldsymbol{O}=\left[\left\{3.045 \times 10^{-6}(A B C)^{2}\right\}+\right.$ $\{19.95(A B C)\}+112] \times 10^{-23}$

Heat of formation for $\boldsymbol{C u O}=\left[\left\{3.75 \times 10^{-4}(A B C)^{2}\right\}+\right.$ $\{13.67(A B C)\}+60.17] \times 10^{-23}$

These equations can be used for the transformation of $A B C$ indices into the approximate heat of formation of the oxides of $\mathrm{Cu}$ at any cubic level.

Figure 6 shows a linear relation of Sanskruti indices with number of formula units and analysis showed higher indices for $\boldsymbol{C} \boldsymbol{u}_{2} \boldsymbol{O}$ compared to $\boldsymbol{C u} \boldsymbol{O}$. Previous studies have shown an association of Sanskruti indices with entropy of octance. ${ }^{15}$ Here we calculated the entropy of both the oxides at different cells from the standard molar entropy. For instance, standard molar entropy for $\boldsymbol{C u} \boldsymbol{O}$ is $93 \mathrm{~J} \mathrm{~mol}^{-1} \mathrm{~K}^{-1}$ so for one formula unit it will be $93 / 6.022 \times 10^{-23} \mathrm{~J} \mathrm{~K}^{-1}$, and for each cell we just multiplied the obtained value with the no. of formula units present in the cell. Similarly entropy for $\boldsymbol{C} \boldsymbol{u}_{2} \boldsymbol{O}$ calculated considering standard molar entropy $43 \mathrm{~J} \mathrm{~mol}^{-1} \mathrm{~K}^{-1}$ (Table 7). Analysis of the data showed a considerable difference between the Sanskruti indices and entropies for the oxides of $\mathrm{Cu}$ (Table 7). Therefore, we determined a mathematical relation for the transformation of Sanskruti indices into approximate entropies of both the oxides of copper as below:

Entropy of $\boldsymbol{C u}_{2} \boldsymbol{O}=\left[\left\{-2.89 \times 10^{-7}(S)^{2}\right\}+\{0.1913(S)\}+\right.$ 48.89] $\times 10^{-23}$

Entropy of $\boldsymbol{C u} \boldsymbol{O}=\left[\left\{-1.081 \times 10^{-8}(S)^{2}\right\}+\{0.1819(S)\}+\right.$ $70.82] \times 10^{-23}$

\section{CONCLUSIONS}

In conclusion, $\mathrm{ABC}$ and Sanskuriti indices of $\boldsymbol{C u}_{2} \boldsymbol{O}$ and $\boldsymbol{C u} \boldsymbol{O}$ showed considerable difference with the experimentally reported entropy and enthalpy of these oxides. On the other hand, Zagreb index and all these indices showed exponential increase with the number of unit cells. On the other hand, these indices showed a linear behavior with number of formula units, suggesting that we may need a slight transformation of these indices for better explanation of physical properties of crystalline compounds."

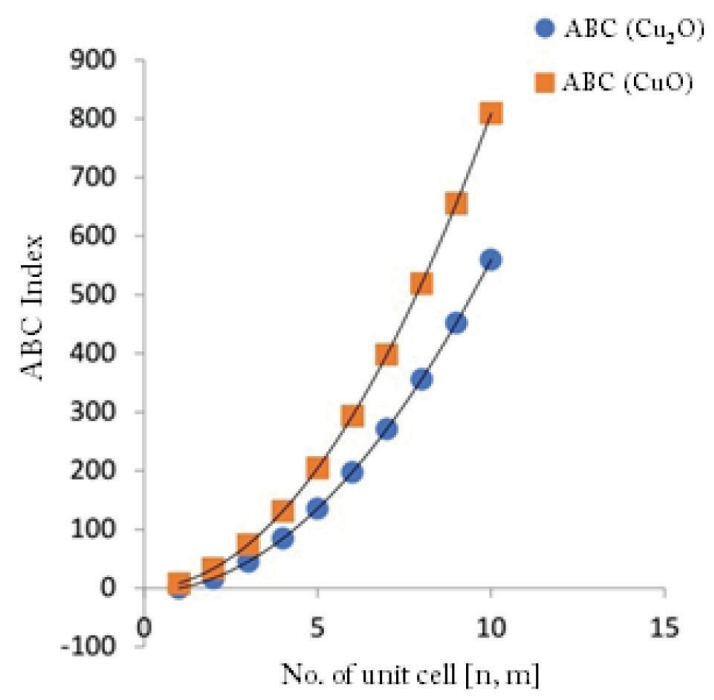

Figure 4. $A B C$ indices of $\mathrm{Cu}_{2} \mathrm{O}$ and $\mathrm{CuO}$ showing exponential increase with number of units cells (at $x$-axis)

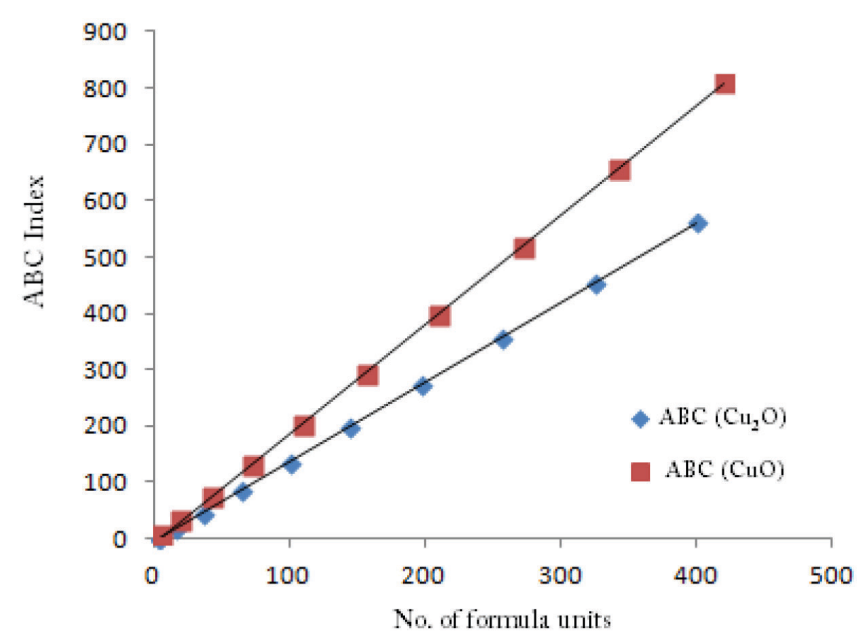

Figure 5. $A B C$ indices of $\mathrm{Cu}_{2} \mathrm{O}$ and $\mathrm{CuO}$ showing linear increase with number of formula units (at x-axis)

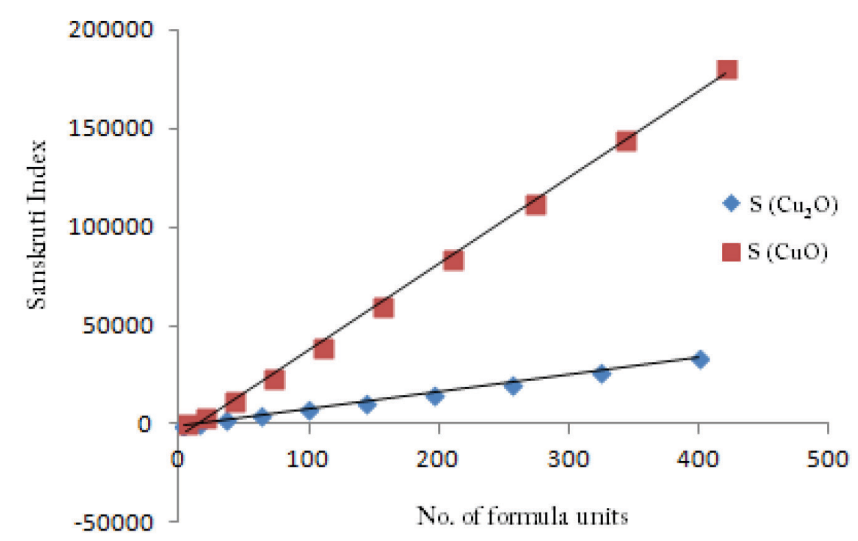

Figure 6. Sanskrit indices of $\mathbf{C u}_{2} \boldsymbol{O}$ and $\mathbf{C u O}$ showing linear increase with number of formula units (at $x$-axis) 


\section{ACKNOWLEDGEMENTS}

The authors are grateful to the anonymous referees for their valuable comments and suggestions that improved this paper. This research is supported by the Start-up Research Grant 2016 of United Arab Emirates University (UAEU), Al Ain, and United Arab Emirates via Grant No. G00002233 and UPAR Grant of UAEU via Grant No. G00002590.

\section{REFERENCES}

1. Babujee, J. B.; Applied Mathematical Sciences 2012, 6, 5383.

2. Baig, A. Q.; Imran, M.; Khalid, W.; Naeem, M.; Can. J. Chem. 2017, 95,674 .

3. Gao, W.; Siddiqui, M. K.; Imran, M.; Jamil, M. K.; Farahani, M. R.; Saudi Pharm. J. 2016, 24, 258.

4. Cotton, F. A.; Wilkinson, G.; Murillo, C. A.; Bochmann, M.; Advanced Inorganic Chemistry, John Wiley and Sons: Hoboken, 1999.

5. Ekimov, E. A.; Sidorov, V. A.; Bauer, E. D.; Melnik, N. N.; Curro, N. J.; Thompson, J. D.; Nature 2004, 428, 5425.

6. Ivanciuc, O.; Curr. Comput. Aided Drug Des. 2013, 9, 153.

7. Soleimani, N.; Nikmehr, M. J.; Tavallaee, H. A.; J. Natl. Sci. Found. Sri Lanka 2015, 43, 127.

8. Gutman, I.; Furtula, B.; MATCH Commun. Math. Comput. Chem. 2012, $68,131$.

9. Gutman, I.; Mathematical Chemistry Monographs No. 1, Kragujevac, 2006.

10. Hu, Y.; Li, X.; Shi, Y.; Xu, T.; Gutman, I.; MATCH Commun. Math. Comput. Chem. 2005, 54, 425.

11. Nikoli, S.; Trinajsti, N.; Toli, I. M. In Complexity in Chemistry; Rouvray, D. H., Bonchev D., eds.; Francis and Taylor: London, 2003, p. 29.
12. Randic, M.; J. Am. Chem. Soc. 1975, 97, 6609.

13. Ramakrishnan, S.; Senbagamalar, J.; Babujee, J. B.; International Journal of Computing Algorithm 2013, 2, 224.

14. Rouvray, D. H.; J. Comput. Chem. 1987, 8, 470.

15. Shegehalli, V. S.; Kanabur, R.; Journal of Mathematics 2016, ID 4341919, doi: 10.1155/2016/4341919.

16. Vukicevic, D.; Furtula, B.; J. Math. Chem. 2009, 46, 1369.

17. Wiener, H.; J. Am. Chem. Soc. 1947, 69, 17.

18. Yang, J.; Sun, H.; He, J. L.; Tian, Y.; Chen, C. F. J.; J. Phys.: Condens. Matter 2007, 19, 346.

19. Shao, Z.; Wu, P.; Zhang, X.; Dimitrov, D.; Liu, J.; IEEE Access. 2018, 6, 27604.

20. Shao, Z.; Wu, P.; Gao, Y.; Gutman, I.; Zhang, X.; Appl. Math. and Comp. 2017, 315, 298.

21. Gutman, I.; Das, K. C.; MATCH Commun. Math. Comput. Chem. 2004, $50,83$.

22. Gutman, I.; Trinajst, N.; Chem. Phys. Lett. 1972, 17, 535.

23. Estrada, E.; Torres, L.; Rodriguez, L.; Gutman, I.; Ind. J. Chem. 1998, $37 A, 849$.

24. Gao, W.; Baig, A. Q.; Khalid, W.; Farahani, M. R.; Maced. J. Chem. Chem. Eng. 2017, 36, 1.

25. Hosamani, S. M.; Journal of Applied Mathematics and Computing 2017, 54,425

26. Chen, K.; Sun, C.; Song. S.; Xue. D.; Cryst. Eng. Commun. 2014, 16, 52.

27. Yuhas, B. D.; Yang, P.; J. Am. Chem. Soc. 2009, 131, 3756.

28. Zhang, J.; Liu, J.; Peng, Q.; Wang, X.; Li, Y.; Chem. Mater. 2006, 18, 867. 